\title{
A Case of Severe Asthma with Eosinophilic Otitis Media Successfully Treated with Anti-IgE Monoclonal Antibody Omalizumab
}

\author{
Azusa Okude, ${ }^{1}$ Etsuko Tagaya, ${ }^{1}$ Mitsuko Kondo, ${ }^{1}$ Manabu Nonaka, ${ }^{2}$ and Jun Tamaoki ${ }^{1}$ \\ ${ }^{1}$ First Department of Medicine, School of Medicine, Tokyo Women's Medical University, \\ 8-1 Kawada-Cho, Shinjuku-ku, Tokyo 162-8666, Japan \\ ${ }^{2}$ Department of Otolaryngology, School of Medicine, Tokyo Women's Medical University, \\ 8-1 Kawada-Cho, Shinjuku-ku, Tokyo 162-8666, Japan
}

Correspondence should be addressed to Jun Tamaoki, jtamaoki@chi.twmu.ac.jp

Received 24 September 2012; Accepted 30 October 2012

Academic Editors: J. Bordon, W. Gao, T. Kawashima, and W. Rodriguez

Copyright ( 2012 Azusa Okude et al. This is an open access article distributed under the Creative Commons Attribution License, which permits unrestricted use, distribution, and reproduction in any medium, provided the original work is properly cited.

\begin{abstract}
A 51-year-old woman had been receiving medical treatment for asthma since she was 21 years old. However, her asthma was poorly controlled despite treatment involving combination inhalation of high-dose corticosteroid and long-acting $\beta_{2}$-aderenergic agonist (LABA) and regularly taking oral steroids. Hearing loss and otorrhea appeared at the age of 44, and she was given a diagnosis of eosinophilic otitis media (EOM) and received medical treatment. In 2007, symptoms of asthma and otitis media deteriorated. In December 2009, omalizumab therapy was started for refractory asthma. After 2 months of omalizumab treatment, not only asthma, but also hearing loss improved. It is suggested that early initiation of omalizumab therapy may inhibit the progression of progressive EOM.
\end{abstract}

\section{Introduction}

The anti-immunoglobulin E (IgE) monoclonal antibody omalizumab was approved in 2005 , by the European Medicines Agency for the treatment of severe asthma [1]. In Japan, omalizumab has been used since 2009, for treating very severe persistent asthma [2]. Omalizumab is expected to exhibit a therapeutic effect on medical conditions associated with eosinophilic inflammation. However, since the approved indication of omalizumab is intractable asthma, very little has been reported about the efficiency of omalizumab on EOM. We describe a case of severe asthma and concurrent intractable EOM in which omalizumab therapy improved the symptoms of both asthma and EOM.

\section{Case Report}

A 51-year-old woman presented with chief complaints of wheezing and hearing loss. She was a nonsmoker with a history of allergic rhinitis. At 21 years of age, bronchial asthma was diagnosed, and she has been receiving medical treatment ever since. However, because the asthma was poorly controlled, she had been regularly taking inhaled corticosteroid (ICS), LABA, antileukotriene agents, and oral steroids (prednisolone (PSL), 10-15 mg/day).

When she was 44 years old, she started to experience symptoms of hearing loss and otorrhea. She was treated with ear drops containing steroids; however, her hearing loss gradually worsened. She was diagnosed with EOM because she had recurrent asthma attacks and otitis media with highly viscous middle ear effusion. PSL dose was increased to $40 \mathrm{mg} /$ day. Subsequently, the steroid dosage was reduced; however, her asthma was poorly controlled, and symptoms of otorrhea and hearing worsened. Omalizumab (Novartis Pharma K.K., Tokyo, Japan) treatment for severe asthma was started from December 12, 2009. Physical findings: Body mass index (BMI) was $21.3 \mathrm{~kg} / \mathrm{m}^{2}$. Rhonchi were heard from the right lung field. Hearing loss was profound in both ears. 
TABLe 1: Clinical laboratory results.

(i) Blood cell count

WBC

Neutro

Lymph

Mono

Eos

Baso

RBC

$\mathrm{Hb}$

$\mathrm{Ht}$

Plt

(ii) Blood chemistry

$\begin{array}{ll}\text { Alb } & 3.7 \mathrm{~g} / \mathrm{dL} \\ \text { AST } & 16 \mathrm{U} / \mathrm{L} \\ \text { ALT } & 19 \mathrm{U} / \mathrm{L} \\ \text { BUN } & 12.5 \mathrm{mg} / \mathrm{dL} \\ \text { Cr } & 0.57 \mathrm{mg} / \mathrm{dL} \\ \text { CRP } & 0.04 \mathrm{mg} / \mathrm{dL} \\ \text { FBS } & 102 \mathrm{mg} / \mathrm{dL}\end{array}$

$\operatorname{IgE}(\mathrm{RIST}) 97.4 \mathrm{lU} / \mathrm{mL}$

(RAST)

Japanese cedar

Dermatophagoides pteronyssinus

Dermatophagoides farina

House dust

$2+$

$3+$

$2+$

$3+$

TABLE 2: The clinical course before and after omalizumab treatment.

\begin{tabular}{|c|c|c|c|c|c|}
\hline $\begin{array}{l}\text { Omalizumab } \\
\text { dose pack (months) }\end{array}$ & $\begin{array}{l}\text { Before } \\
\text { treatment }\end{array}$ & $\begin{array}{l}\text { Post } 2 \text { months } \\
\quad(5 \sim 8 \mathrm{~W})\end{array}$ & $\begin{array}{l}\text { Post } 4 \text { months } \\
\quad(13 \sim 16 \mathrm{~W})\end{array}$ & $\begin{array}{l}\text { Post } 6 \text { months } \\
\quad(21 \sim 24 \mathrm{~W})\end{array}$ & $\begin{array}{l}\text { After } \\
1 \text { year }\end{array}$ \\
\hline $\operatorname{IgE}(\mathrm{IU} / \mathrm{mL})$ & 97.4 & 181 & 159 & 144 & 102 \\
\hline PEF (L/sec): morning/evening & $210 / 290$ & $280 / 330$ & $280 / 310$ & $220 / 280$ & $230 / 320$ \\
\hline PSL dose (mg/day) & 15 & 10 & 10 & $10 / 5$ & 15 \\
\hline $\begin{array}{l}\text { Rescue frequency } \\
\text { (times/28 day) }\end{array}$ & 12 & 0 & 0 & 7 & 10 \\
\hline \multicolumn{6}{|l|}{ Daily life (days/28 days) } \\
\hline No difficulty & 0 & 5 & 28 & 16 & 4 \\
\hline Slight difficulty & 19 & 23 & & 7 & 24 \\
\hline Extreme difficulty & 9 & & & 5 & \\
\hline Deep sleep (days/28 days) & 20 & 28 & 28 & 24 & 28 \\
\hline Cough $\quad$ Mild & 15 & 14 & 8 & 7 & 9 \\
\hline (days/28 days) strong & 3 & 0 & 1 & 5 & 0 \\
\hline none & 9 & 14 & 19 & 16 & 16 \\
\hline $\begin{array}{l}\text { No symptom days } \\
\text { (days/28 days) }\end{array}$ & 20 & 28 & 27 & 21 & 25 \\
\hline Lung function: $\mathrm{FEV}_{1}(\mathrm{~L})$ & 1.93 & & 2.34 & & \\
\hline$\% \mathrm{FEV}_{1}(\%)$ & 63.9 & & 76.4 & & \\
\hline $\mathrm{PEF}(\mathrm{L} / \mathrm{sec})$ & 4.89 & & 5.84 & & \\
\hline
\end{tabular}

TABLE 3: Diagnostic criteria of eosinophilic otitis media.

(i) Major: otitis media with effusion or chronic otitis media with eosinophil-dominant effusion

(ii) Minor

(1) Highly viscous middle ear effusion

(2) Resistance to conventional treatment for otitis media

(3) Association with bronchial asthma

(4) Association with nasal polyposis

Definitive case: major + two or more minor criteria.

Exclusion criteria: Churg-Strauss Syndrome and hypereosinophilic syndrome. 


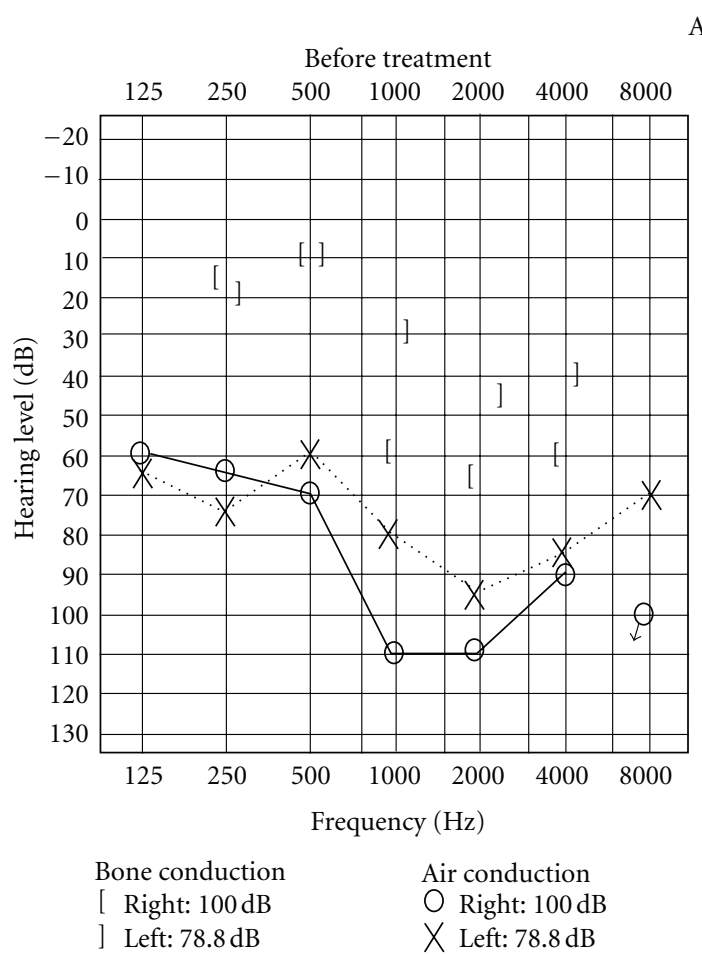

Audiogram
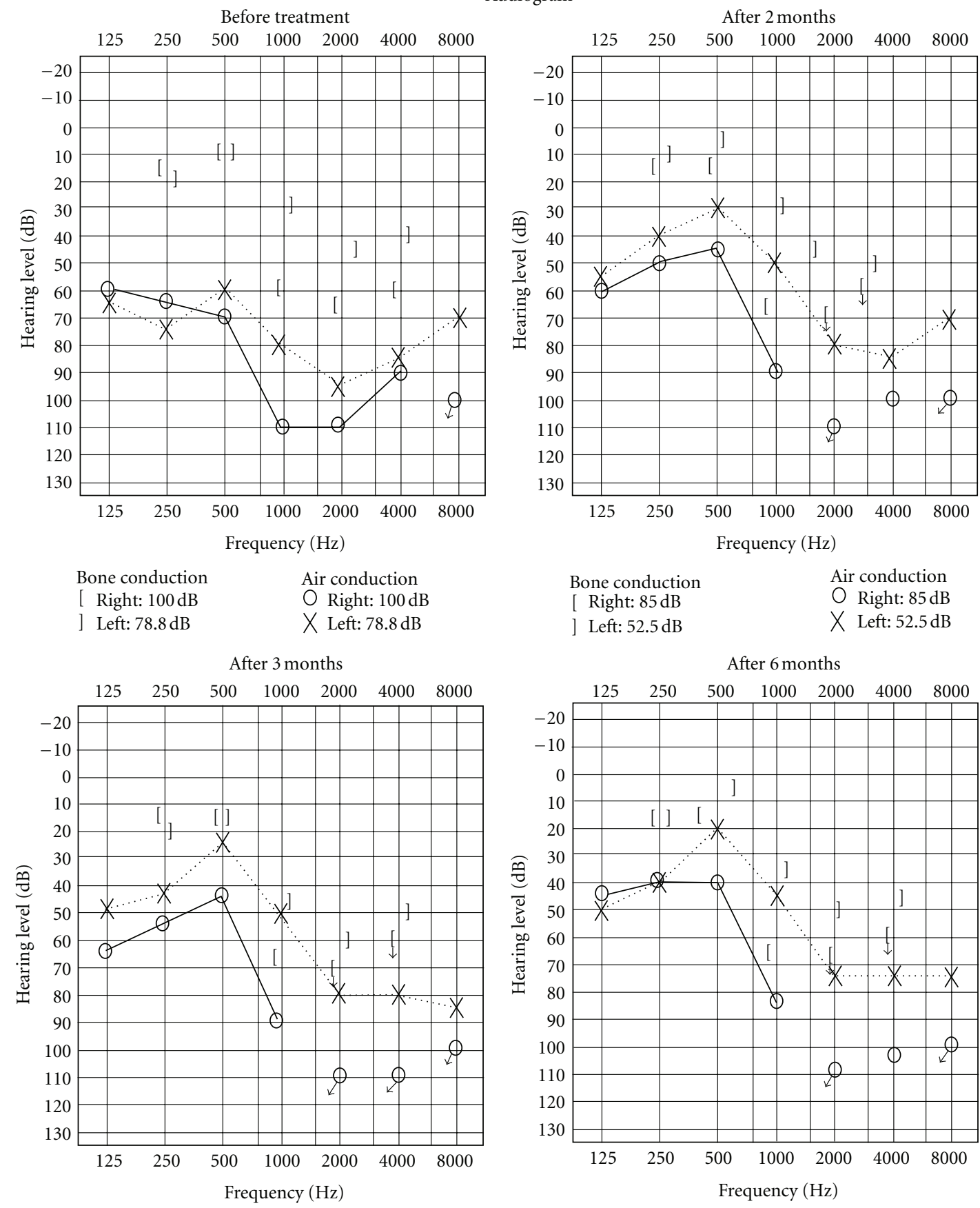
Bone conduction
Air conduction
[ Right: $85 \mathrm{~dB}$
Right: $85 \mathrm{~dB}$
] Left: $52.5 \mathrm{~dB}$
X Left: $52.5 \mathrm{~dB}$

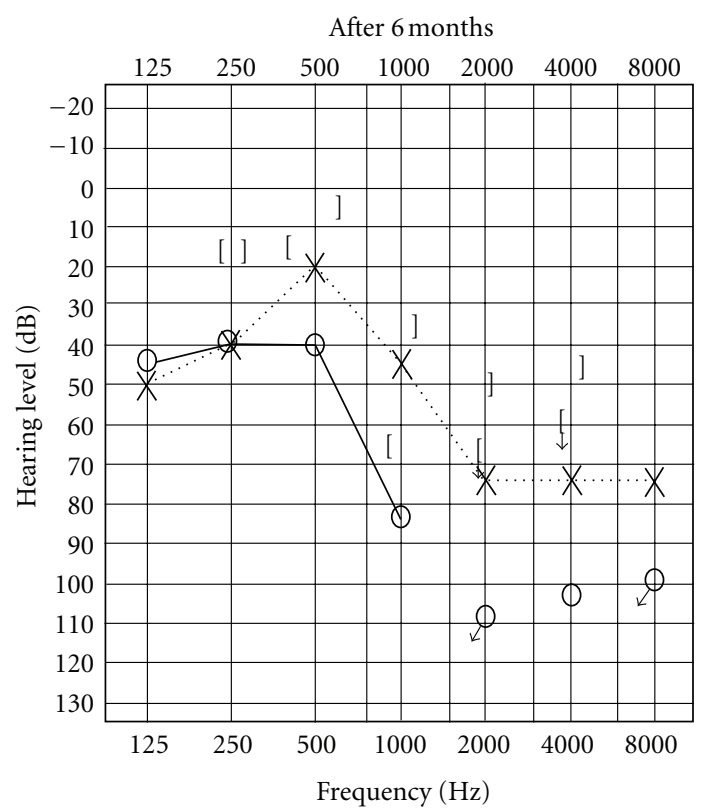

$\begin{array}{ll}\text { Bone conduction } & \text { Air conduction } \\ \text { [ Right: } 83.8 \mathrm{~dB} & \text { O Right: } 83.8 \mathrm{~dB} \\ \text { ] Left: } 48.8 \mathrm{~dB} & \text { X Left: } 48.8 \mathrm{~dB}\end{array}$

FIgURE 1: The changes of the audiogram before and after omalizumab treatment. Before omalizumab treatment, the patient had developed impaired hearing both by air and bone conduction; however, after the second omalizumab administration, air conduction hearing improved in the low-frequency range in both ears.

\section{Clinical Laboratory Results (Table 1)}

The patient was receiving $10 \mathrm{mg} /$ day PSL; no increase was observed in the peripheral blood eosinophil count.
The total IgE level was $97.4 \mathrm{IU} / \mathrm{mL}$. The results of the radioallergosorbent test (RAST) were positive for Japanese cedar, Dermatophagoides pteronyssinus, Dermatophagoides farinae, and house dust. The patient tested negative for 
antineutrophil cytoplasmic antibodies (ANCAs). Chest Xray showed no abnormal findings. The patient had no symptoms indicative of allergic bronchopulmonary aspergillosis (ABPA) or Churg-Strauss syndrome.

\section{Clinical Course}

Total IgE level slightly increased due to omalizumab therapy. Regarding lung function, an increase in the mean peak expiratory flow (PEF), along with improvement in the $\mathrm{FEV}_{1} / \mathrm{FVC}$, was observed at 2 months and 4 months after initiating omalizumab therapy. The use of short-acting $\beta_{2}$ stimulant (SABA) was significantly decreased (Table 2 ). Because improvement was observed at 4 months after the start of omalizumab therapy, PSL dose was reduced. However, after 1 year, exacerbation of asthma symptoms with concurrent infection was observed, with simultaneous PEF decrease. The audiogram indicated that, before omalizumab treatment, the patient had developed impaired hearing both by air and bone conduction; however, after the second omalizumab administration, air conduction hearing improved in the low-frequency range in both ears. Improved hearing has been maintained (Figure 1). Amelioration of both asthma symptoms and hearing has contributed to a better quality of life (QOL) of the patient.

\section{Discussion}

Omalizumab is an anti-IgE monoclonal antibody, which binds to free IgE in the blood and inhibits the binding between FceRI and IgE on the mast cell membrane. The inhibition of the binding between FceRI and IgE prevents degranulation of inflammatory mediators such as histamine and interleukins from the mast cells, thereby inhibiting the allergic response [2]. Although omalizumab is indicated for the treatment of severe asthma, omalizumab is expected to have a therapeutic effect on conditions associated with eosinophilic inflammation.

EOM, first described by Matsutani et al. in 1995 [3], is an intractable otitis media characterized by heavy eosinophilic infiltration and high viscous mucoid effusion, and it is found in patients with adult-onset asthma. The essential diagnostic criterion includes otitis media with effusion in which the middle ear fluid contains eosinophils. A definitive diagnosis is established when the aforementioned condition is observed in conjunction with bronchial asthma, nasal polyps, history of dural incision, or resistance to antimicrobial agents (Table 3) [4]. Although the cause of EOM is not clear, considering that the middle ear fluid contains a high concentration of eosinophil cationic protein (ECP) derived from eosinophils [5] and the report by Nonaka et al. [6] on the high concentration of interleukin-5 (IL-5), eosinophilic inflammation is thought to be induced in the middle ear cavity by some stimuli through the Eustachian tube. The clinical features of EOM are that women aged 40-69 years are most susceptible, and EOM affects both ears in about $80 \%$ of causes. EOM occurs in conjunction with bronchial asthma, nasal polyps, or sinusitis. In particular, EOM is found in
$90 \%$ of patients with bronchial asthma [7]. EOM is often intractable, and can lead to total deafness.

In EOM cases, the biopsy of the middle ear mucous membrane shows eosinophilic infiltration, goblet cell metaplasia, granulation, and fibril formation in the epithelial and subepithelial parts. The clinical features of EOM, that is, high concentration of eosinophils in the middle ear fluid, eosinophilic infiltration in the middle ear mucous membrane, goblet cells metaplasia, and fibril formation in the advanced disease stage, are similar to those of asthma in which eosinophilic inflammation occurs in the lower respiratory tract.

In the present case, although omalizumab was used to treat severe asthma, it improved not only the asthma, but also the EOM. During the first time, $150 \mathrm{mg} /$ dose of omalizumab was administered at 4-week intervals, according to the pretreatment IgE concentration. However, weakening of the therapeutic effect was often observed as early as 2 weeks after treatment initiation. Thus, the dose of omalizumab was increased to $300 \mathrm{mg}$ on the concentration basis of IgE measured before steroid therapy. After increasing the doses, the symptoms improved significantly, and the therapeutic effect was maintained.

The IgE concentration often decreased in patients with severe asthma who are measured before omalizumab therapy [8]. In the present case, the pretreatment IgE concentration was $97.4 \mathrm{IU} / \mathrm{mL}$, which was rounded to $100 \mathrm{IU} / \mathrm{mL}$, and the dose of $150 \mathrm{mg}$ was selected first; however, the dose was later increased to $300 \mathrm{mg}$ to obtain a better result. Hence, upward dose adjustment may improve the clinical outcome.

\section{Conclusions}

Omalizumab improved the asthma symptoms and hearing in a patient with severe persistent asthma with interactive EOM and progressive hearing loss. In patients with severe asthma, treatment of the complication symptoms is indispensable. Early initiation of omalizumab therapy may inhibit the progression of complicated EOM.

\section{References}

[1] Global Initiative for Asthma, 2005.

[2] S. Holgate, T. Casale, S. Wenzel, J. Bousquet, Y. Deniz, and C. Reisner, "The anti-inflammatory effects of omalizumab confirm the central role of IgE in allergic inflammation," Journal of Allergy and Clinical Immunology, vol. 115, no. 3, pp. 459-465, 2005.

[3] S. Matsutani, T. Kobayashi, and T. Kousaka, "Eosionophilic otitis media," Otolaryngology-Head and Neck Surgery, vol. 67, no. 8, pp. 712-713, 1995.

[4] Y. Iino, S. Tomioka-Matsutani, A. Matsubara, T. Nakagawa, and M. Nonaka, "Diagnostic criteria of eosinophilic otitis media, a newly recognized middle ear disease," Auris Nasus Larynx, vol. 38, no. 4, pp. 456-461, 2011.

[5] Y. Iino, H. Nagamine, T. Yabe, and S. Matsutani, "Eosinophils are activated in middle ear mucosa and middle ear effusion of patients with intractable otitis media associated with bronchial asthma," Clinical and Experimental Allergy, vol. 31, no. 7, pp. 1135-1143, 2001. 
[6] M. Nonaka, A. Fukumoto, C. Ozu et al., "IL-5 and eotaxin levels in middle ear effusion and blood from asthmatics with otitis media with effusion," Acta Oto-Laryngologica, vol. 123, no. 3, pp. 383-387, 2003.

[7] T. Kawano, J. Ishitoya, and M. Tsukuda, "Sinusitis with eosinophilic otitis media," Practica Oto-Rhino-Laryngologica, vol. 100, no. 9, pp. 715-724, 2007.

[8] P. J. Thompson, N. L. Misso, and J. Woods, "Omalizumab (Xolair) in patients with steroid-resistant asthma: lessons to be learnt," Respirology, vol. 12, no. 3, pp. 29-34, 2007. 


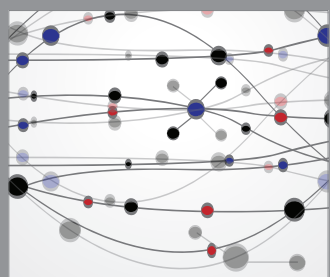

The Scientific World Journal
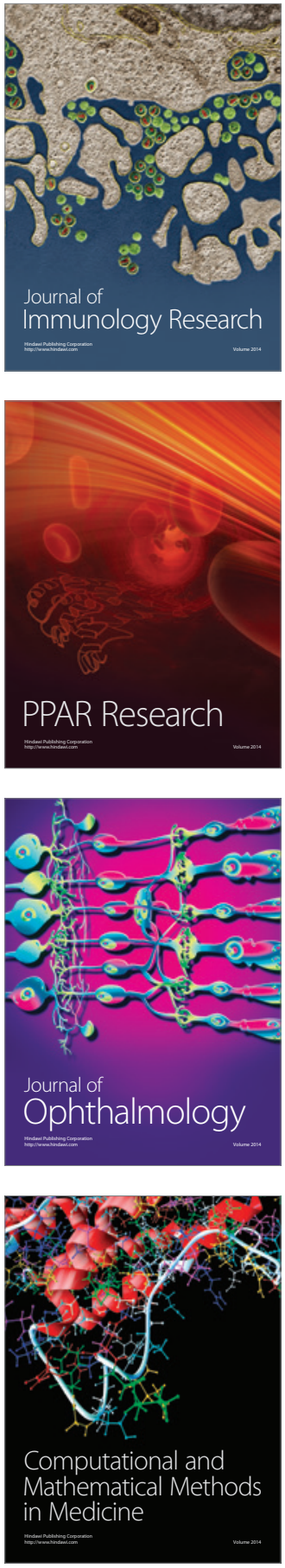

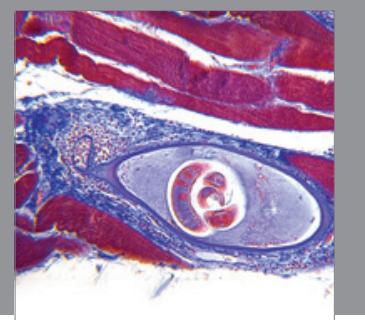

Gastroenterology

Research and Practice
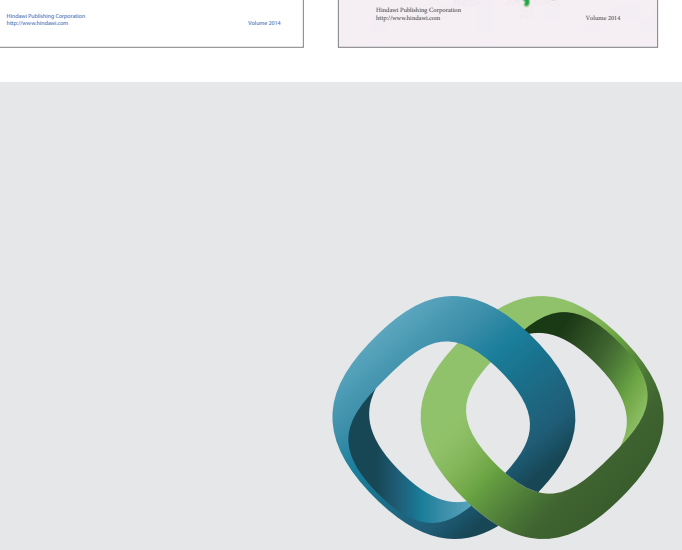

\section{Hindawi}

Submit your manuscripts at

http://www.hindawi.com
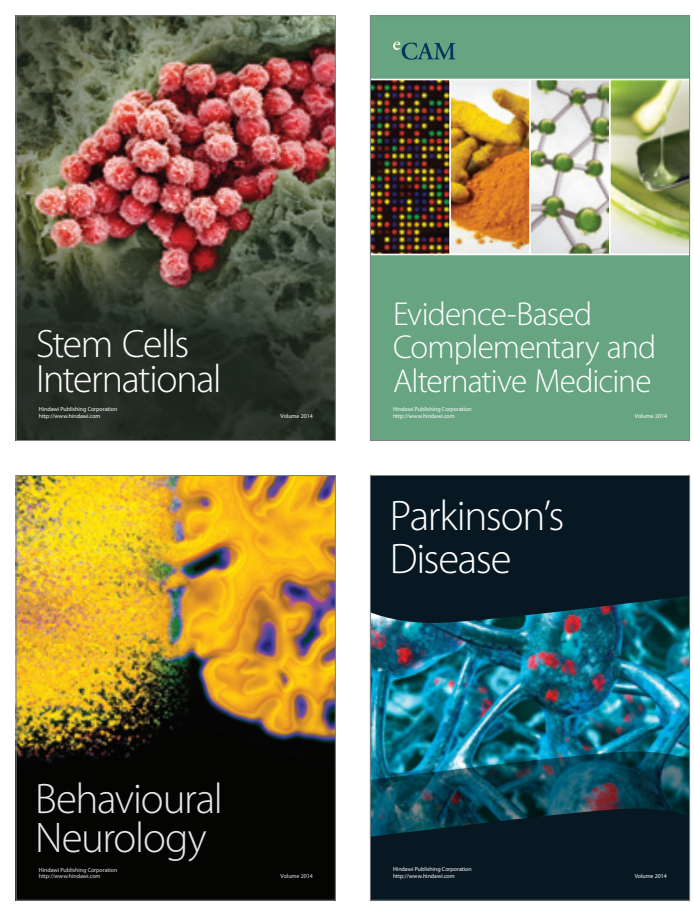

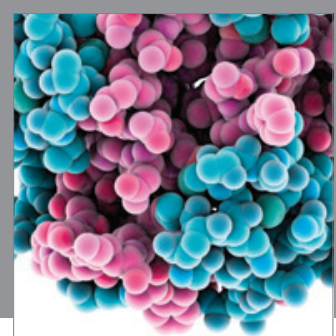

Journal of
Diabetes Research

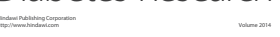

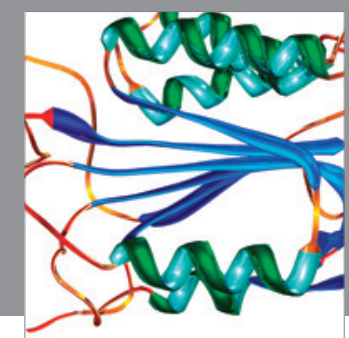

Disease Markers
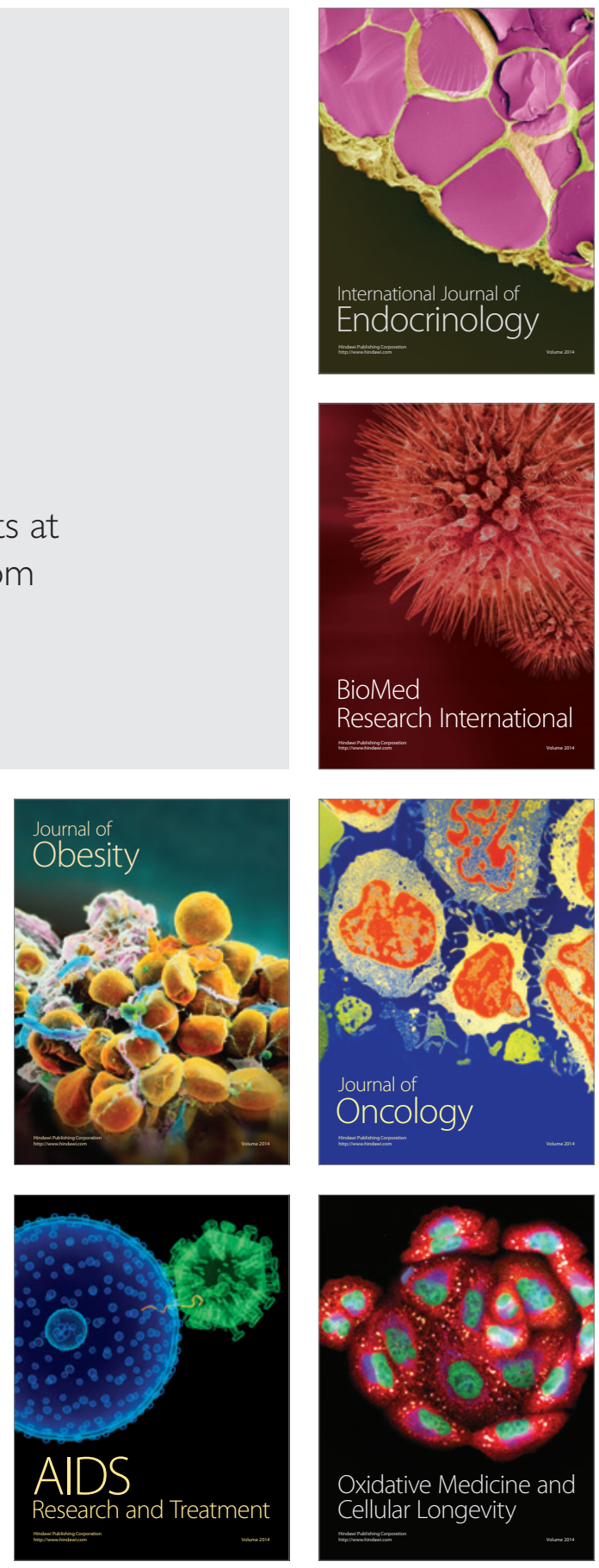